\title{
Economic Evaluation and Research of Day-ahead Optimal Dispatch of the Microgrid
}

\author{
Yuman Zhang ${ }^{1, a}$ \\ ${ }^{1}$ North China Electric Power University, Beijing, China \\ 2291229717@qq.com
}

Keywords: Microgrid; Economy; Genetic algorithm; Day-ahead dispatch; Load power supply unit price

\begin{abstract}
Aiming at the day-ahead optimal problem of microgrid, according to the accurate wind and light output data within 24 hours, this paper establishes the optimization model. In the case of adding storage battery regulation, the regulation and distribution model of the storage battery in one day is established, and by introducing 0-1 variables, the charge and discharge of the storage battery are restricted. The abandoned air and abandoned light are taken as slack variables, and the genetic algorithm is used to search the model. After convergence analysis, the optimal solution is obtained, so as to obtain the decline situation of the average load power supply unit price, and meanwhile through the situation analysis of the charge and discharge of the storage battery, the conclusion that the storage battery can compensate the load demand and reduce the cost of the power supply can be obtained.
\end{abstract}

\section{Introduction}

With the continuous popularization and application of microgrid, the maximization of the economic, technical and environmental benefits of microgrid has become an important research topic, and the economy is an important factor to promote the continuous popularization and application of microgrid. In order to optimize the economy and comprehensive benefits of microgrid, the economic evaluation of microgrid operation is required, that is, taking the minimum average power supply cost of the load as the goal, the power supply structure of load of each period, all-day total power supply cost and the average power purchase unit price of the load can be calculated, and the utilization situation of renewable energy and the influence of the storage battery after participating in the regulation can be obtained.

\section{The Day-ahead Dispatch Model of Microgrid}

For the economic evaluation value, taking the minimum average power supply cost of the load as the goal, by regulating the grid and the output of each micro source, the total power supply cost of microgrid can be minimized. Considering the function of storage battery, the cost of power supply includes the cost of purchase and sale of electricity, the cost of electricity generation of renewable energy and the cost of the charge and discharge of the storage battery.

$$
\min C_{Z}=\sum_{i=1}^{96}\left[0.52\left(x_{1 i}+x_{2 i}+x_{3 i}\right)+0.75\left(y_{1 i}+y_{2 i}+y_{3 i}\right)-C_{M D}\left(x_{2 i}+y_{2 i}+n_{2 i}\right)+C_{G D}\left(z_{1 i}+z_{2 i}\right)+0.2\left(x_{3 i}+y_{3 i}+z_{2 i}\right)\right]
$$


The meaning and definition of each symbol are as follows:

\begin{tabular}{ll}
\hline Symbol & Definition \\
\hline$x_{1 i}$ & The electricity capacity of the load given by the fan \\
$x_{2 i}:$ & $\begin{array}{l}\text { The selling electricity capacity generated by the fan to } \\
\text { the grid }\end{array}$ \\
$x_{3 i}$ & $\begin{array}{l}\text { The charging capacity generated by the fan to the } \\
\text { storage battery }\end{array}$ \\
$y_{1 i}$ & $\begin{array}{l}\text { The electricity capacity of the load given by the } \\
\text { nhntnvnltairc }\end{array}$ \\
$y_{2 i}:$ & $\begin{array}{l}\text { The selling electricity capacity generated by the } \\
\text { photovoltaics to the grid }\end{array}$ \\
$y_{3 i}$ & $\begin{array}{l}\text { The charging capacity generated by the photovoltaics } \\
\text { to the storage battery }\end{array}$ \\
$z_{1 i}$ & $\begin{array}{l}\text { The load given by buying electricity from the grid } \\
z_{2 i}\end{array}$ \\
$n_{1 i}$ & $\begin{array}{l}\text { The charging of the storage battery by buying } \\
\text { electricity from the grid }\end{array}$ \\
$n_{2 i}$ & $\begin{array}{l}\text { The discharging capacity of the storage battery to the } \\
\text { load }\end{array}$
\end{tabular}

A series of constraints on the model include:

Power Balance Constraint. Considering the function of storage battery, the sum of the wind power usage, photoelectric usage and purchasing electric quantity, and the discharging capacity of the storage battery to the load is equal to the total load, that is:

$$
x_{1 i}+y_{1 i}+Z_{1 i}+n_{1 i}=q_{i}
$$

$q_{i}$ is the electricity consumption of the load in $i$ th period.

Renewable energy needs to be selectively used. The power generated by a draught fan (photovoltaics) should be only greater than the sum of the power supplied to the load, discharged to the battery, and sold to the grid, that is:

$$
\begin{aligned}
& y_{1 i}+y_{2 i}+y_{3 i} \leq y_{G} \\
& x_{1 i}+x_{2 i}+x_{3 i} \leq x_{F}
\end{aligned}
$$

Constraint of the Charge and Discharge Capacity of the Storage Battery. For the storage battery, in the process of participating in optimizing operation of the system, the energy status of it must meet the same constraints at the beginning and end of the dispatching cycle, that is, the total charge is equal to the total discharge.

$$
\sum_{i=1}^{96}\left(x_{3 i}+y_{3 i}+z_{2 i}\right) \times a_{i}=\sum_{i=1}^{96}\left(n_{1 i}+n_{2 i}\right) \times b_{i}
$$

In the formula, $a_{i}$ and $b_{i}$ are respectively the charging state and discharging state of the storage battery, among it, $a_{i} \in\{0,1\}, b_{i} \in\{0,1\}$. The storage battery cannot be charged and discharged at the same time, therefore, the charging and discharging state of the storage battery should satisfy $a_{i} \bullet b_{i}=0$

Constraint of the Storage Battery Operation. For the storage battery, in order to prevent the overcharge and over discharge, its SOC(The ratio of the battery remaining capacity to the battery capacity)should satisfy the constraints of the upper and lower limiting value. 


$$
S_{\min }<S_{0}+\frac{\sum_{i=1}^{96}\left(x_{3 i}+y_{3 i}+z_{2 i}\right) \times a_{i}-\sum_{i=1}^{96}\left(n_{1 i}+n_{2 i}\right) \times b_{i}}{4 E_{b}}<S_{\max }
$$

In the formula, $S_{\min }$ and $S_{\max }$ are respectively the maximum and minimum residual capacity of the storage battery. When SOC reaches the maximum value of the battery $\left(S_{\max }=0.95\right)$, the battery stops charging. When SOC reaches the minimum value $\left(S_{\min }=0.3\right)$, the battery stops discharging. The battery capacity $E_{b}=300 \mathrm{kWh}$, and the initial SOC state of the storage battery $S_{0}=0.4$

At the same time, the charge and discharge power of the storage battery and the charge and discharge times of the storage battery are related to the battery life. The maximum charge and discharge power per unit time is $20 \%$ of the rated capacity of the storage battery, that is $60 \mathrm{~kW}$. Charge and discharge times are limited to 8 times.

$$
\begin{gathered}
x_{3 i}+y_{3 i}+z_{2 i} \leq 60, \quad n_{1 i}+n_{2 i} \leq 60 \\
\sum_{i=2}^{96}\left(a_{i}-a_{i-1}\right) \leq 8, \quad \sum_{i=2}^{96}\left(b_{i}-b_{i-1}\right) \leq 8
\end{gathered}
$$

Constraint of the Maximum Transmission Power that Allows Interaction between the Microgrid and the Main Network. Microgrid can exchange power with the main network freely and bilaterally. The allowed exchange power of microgrid and gird does not exceed $150 \mathrm{~kW}$ (exchange power that is the purchase / sale of electric power).

$$
\begin{gathered}
z_{1 i}+z_{2 i} \leq 150 \\
x_{2 i}+y_{2 i}+n_{2 i} \leq 150
\end{gathered}
$$

\section{The Model Optimization Solution based on Genetic Algorithm}

Algorithm Steps. The cost of electricity generation should be minimized, and meanwhile according to the requirement of the environment, renewable energy needs to be selectively used. Also the function of the storage battery should be considered and it is allowed that microgrid can exchange the power with the grid. The restriction of many constraints makes this problem become a problem of multi-objective optimization, and the objective function contains discontinuous functions, which are difficult to solve by the traditional optimization algorithm. Therefore, in order to solve this problem, genetic algorithm will be adopted. The main steps of the basic genetic algorithm are as follows:

Step 1. The optimization searching parameters are determined. The encoding length is set, and the encoding is conducted.

Step 2. A set of initial solutions is generated randomly to form the initial population $P(t)$. Starting from it, iterative process begins, and the maximum iterations is set.

Step 3. The fitness of individuals in a population is calculated, and the fitness of each individual is used to evaluate the advantage and disadvantage of each individual, thus the size of the genetic opportunity is determined.

Step 4. Selection was conducted to select individuals with higher fitness in the current population as parent to reproduce.

Step 5. According to the crossover probability $P_{c}$ the crossover operation is conducted.

Step 6. According to the mutation probability $P_{m}$, the mutation operation is conducted.

Step 7. Through selection, crossover and mutation operations, the population $P(t)$ obtains the next generation population $P(t+1)$.

Step 8. Determine whether it satisfies the output condition, if it satisfies, the calculation is 
terminated, otherwise, step 2 is returned.

The population continues to undergo genetic and evolutionary manipulation, and each time, in accordance with the rule of survival of the fittest, individuals with higher fitness should be passed on to the next generation, finally the required result can be obtained.

Solving Process. The selection of genetic algorithm parameters is as follows: the initial population size is 50 ; the maximum generation number of inheritance is 12 ; the crossover probability is 0.9 ; the mutation probability is 0.09 ; the reserved generation number of the optimal individual is 2 ; and the number of reserved optimal individuals per generation is 4 .

Step1. The initialization of groups: The size of the population $M$, the crossover probability $P_{c}$, and the mutation probability $P_{m}$ is determined. The initial output power is determined by the following formula.

$$
P_{i}=P_{i \min }+\alpha_{i}\left(P_{i \max }-P_{i \min }\right)
$$

In the formula: $P_{i}$ refers to the output power of micro power source, $i=1,2,3$; when $i=1, P_{i}$ refers to the power output by fan; when $i=2, P_{i}$ refers to the power output by photovoltaics; when $i=3, P_{i}$ refers to the power output by the storage battery; $P_{\max }, P_{\min }$ respectively refer to the upper and lower limit; $\alpha_{i}$ is a random number between $0-1$.

Step2. The constraint will be plugged into: The population obtained in the initialization of the population only satisfies the constraints. Therefore, the output power of each micro power source $P_{i, c}$ that satisfies the power conservation constraint should be worked out.

$$
\begin{gathered}
x_{1 i}+y_{1 i}+z_{1 i}+n_{1 i}=\mathrm{P}_{i c} \\
x_{1 i}+x_{2 i}+x_{3 i}=x_{F} \\
y_{1 i}+y_{2 i}+y_{3 i}=y_{G}
\end{gathered}
$$

Step3. The evaluation of the individual fitness: The fitness function values of each individual in the population are calculated, meanwhile, the electricity generation cost of the micro power source corresponding to the $i$ th individual and the total cost of electricity generation of microgrid are calculated.

Step4. Selection: Roulette wheel selection method mechanism is adopted. That is, the individual with the lowest total cost was chosen as the best individual.

Step5. Population crossover: This paper uses the real number crossing method of SBX mentioned in the literature. $u_{i}$ is taken as the random number between $0-1 . \lambda_{c}$ is the any real number greater than zero. By $u_{i}$ and $\lambda_{c}$, the parameter $\beta_{q i}$ that represents the crossover operation can be obtained.

$$
\beta_{q i}=\left\{\begin{array}{l}
\left(2 u_{i}\right)^{1 \backslash \lambda_{2}+1}, u_{i} \leq 0.5 \\
\left(\frac{1}{2\left(1-u_{i}\right.}\right)^{1 / \lambda_{2}+1}, u_{i}>0.5
\end{array}\right.
$$

The greater the $\lambda_{c}$, the closer the generations are to their fathers. By $\beta_{q i}$, the generation after the crossover is obtained, that is:

Among it,

$$
\begin{gathered}
P_{11}=\left[p_{1}^{(1, t+1)}, p_{2}^{(1, t+1)}, \ldots p_{N}{ }^{(1, t+1)}\right] \\
P_{21}=\left[p_{1}^{(2, t+1)}, p_{2}^{(2, t+1)}, \ldots p_{N}^{(2, t+1)}\right]
\end{gathered}
$$

$$
\begin{aligned}
& P_{i}^{(1, t+1)}=0.5\left[\left(1+\beta_{q i}\right) p_{i}^{(1, t)}+\left(1-\beta_{q i}\right) p_{i}^{(2, t)}\right] \\
& P_{i}^{(2, t+1)}=0.5\left[\left(1-\beta_{q i}\right) p_{i}^{(1, t)}+\left(1+\beta_{q i}\right) p_{i}^{(2, t)}\right]
\end{aligned}
$$


Among it: $P_{11}, P_{21}$ respectively refer to the offspring of the two crossed individuals. $P_{i}^{1, t}, P_{i}^{2, t}$ refer to the value of the parent before the crossover. $P_{i}^{(1, t+1)}, P_{i}^{(2, t+1)}$ refer to the value of the offspring after the crossover.

Step 6. Genetic variation: This paper adopts the mutation operator coded by SBX. After variation, the value $y_{i}$ of $P_{i}$ is:

$$
y_{i}=P_{i}+\left(P_{i \max }-P_{i \min }\right) \delta_{i}
$$

Among it, $\delta_{i}=\left(2 r_{i}\right)^{1 / \eta_{m}+1}-1,0 \leq r_{i} \leq 0.5$

In the formula: $\delta_{i}$ refers to the mutation parameter. ${ }^{r_{i}}$ is the random number between $0-1$. $\eta_{m}$ is the any real number greater than zero.

Step 7. Test whether the mutant population meets the constraints: Since after selection, crossover, crossover optimization, and mutation, the constraints that the power combinations originally satisfy may be destroyed, therefore, it is necessary to test whether they satisfy all constraints. If they still satisfy the constraint, they can go directly to the steps that select the best individual. If they do not satisfy all the constraints, then they need to go back to the Step 3 to loop until all the constraints are satisfied.

Step8. The best individual of this iteration is selected: The cost of each individual obtained by step 9 is respectively calculated. The individual with the smallest cost function value is chosen as the best individual for this iteration.

Step9. Determination of searching termination conditions: The individual that satisfies the following two conditions can be considered as the best individual. The first one is that it should achieve the required iterations. The second one is that it should satisfy the relation.

$$
\frac{\left|f_{\cos t, t}-f_{\cos t, t-1}\right|}{\left|f_{\cos t, t}\right|}
$$

Genetic algorithm is essentially a heuristic random search algorithm, so the results obtained by the genetic algorithm are different each time. Under the constraints given by the independent variable, the seamless encoding is conducted(that is, such encoding way can express all feasible solutions of the solution space). Therefore, theoretically, genetic algorithm always has many opportunities to get the global optimal solution rather than local optimal results.

\section{The Example Analysis}

Basic Data. The computing time is 24 hours. The time interval is 15 minutes. The installed capacity of the fan is $250 \mathrm{~kW}$ and its generation cost is 0.52 yuan $/ \mathrm{kWh}$. The installed capacity of photovoltaics is $150 \mathrm{~kW}$ and its generation cost is 0.75 yuan/kWh. It is assumed that the storage battery loss can be ignored. The rated capacity of the storage battery is $300 \mathrm{kWh}$. The operating range of SOC on the storage battery is from 0.3 to 0.95 . The initial SOC value is 0.4 . The cost from charging to discharging is 0.2 yuan $/ \mathrm{kWh}$. The limited times of charging and discharging are 8 . The price of selling electricity and buying electricity: the price of selling electricity and buying electricity is shown in Table 1.

Table 1. Electricity sale and electricity purchase price

\begin{tabular}{|c|c|c|c|c|c|c|}
\hline Period & $0: 00 \sim 7: 00$ & $7: 00 \sim 10: 00$ & $10: 00 \sim 15: 00$ & $15: 00 \sim 18: 00$ & $18: 00 \sim 21: 00$ & $21: 00 \sim 0: 00$ \\
\hline $\begin{array}{l}\text { Electricity } \\
\text { sale price } \\
\text { (Yuan/kWh) }\end{array}$ & 0.22 & 0.42 & 0.65 & 0.42 & 0.65 & 0.42 \\
\hline $\begin{array}{l}\text { Electricity } \\
\text { purchase price } \\
\text { (Yuan/kWh) }\end{array}$ & 0.25 & 0.53 & 0.82 & 0.53 & 0.82 & 0.53 \\
\hline
\end{tabular}

Permissible exchange power between micro-grid and grid will not be beyond 150kW. The load 
forecasting, fan and photovoltaics future power are totally accurate within 24 hours. The specific data are shown in Table 2.

Table 2. Load forecasting, fan and photovoltaics future output

\begin{tabular}{|c|c|c|c|c|c|c|c|c|c|c|c|}
\hline $\begin{array}{c}\text { serial } \\
\text { number }\end{array}$ & $\operatorname{load}(\mathbf{k W})$ & $\begin{array}{l}\text { draught- } \\
\text { fan }(\mathbf{k W})\end{array}$ & \begin{tabular}{|c|} 
photovoltai \\
$-\operatorname{cs}(\mathbf{k} \mathbf{W})$ \\
\end{tabular} & $\begin{array}{c}\text { serial } \\
\text { number }\end{array}$ & $\operatorname{load}(\mathbf{k W})$ & $\begin{array}{l}\text { draught- } \\
\text { fan }(\mathbf{k W})\end{array}$ & \begin{tabular}{|c|} 
photovoltai \\
$-\operatorname{cs}(\mathbf{k W})$
\end{tabular} & $\begin{array}{c}\text { serial } \\
\text { number }\end{array}$ & $\operatorname{load}(\mathbf{k W})$ & $\begin{array}{l}\text { draught- } \\
\text { fan }(\mathbf{k} \mathbf{W})\end{array}$ & \begin{tabular}{|c} 
photovoltai \\
-cs(kW) \\
\end{tabular} \\
\hline 1 & 64.3 & 163.1 & 0 & 33 & 154.1 & 246.62 & 46.08 & 65 & 203.5 & 21.07 & 41.64 \\
\hline 2 & 65.5 & 201.47 & 0 & 34 & 157.4 & 250 & 53.66 & 66 & 207.2 & 27.11 & 23.39 \\
\hline 3 & 66.7 & 154.26 & $\overline{0}$ & 35 & 156.5 & 179.02 & 36.29 & 67 & 207 & 43.75 & 24.86 \\
\hline 4 & 66.9 & 140.29 & $\overline{0}$ & 36 & 155.5 & 144.06 & 49.64 & 68 & 206.9 & 53.45 & 20.6 \\
\hline 5 & 67.5 & 200.29 & $\overline{0}$ & 37 & 144 & 197.36 & 76.96 & 69 & 215.5 & 19.61 & 17.4 \\
\hline 6 & 67.7 & 250 & 0 & 38 & 142.2 & 227.91 & 66.81 & 70 & 223.9 & 9.95 & 15.06 \\
\hline 7 & 68 & 154.26 & 0 & 39 & 142.1 & 215.96 & 55.57 & 71 & 225 & 72.19 & 13.59 \\
\hline 8 & 68.2 & 125.64 & 0 & 40 & 142.1 & 218.44 & 88.62 & 72 & 225.5 & 120.28 & 22.08 \\
\hline 9 & 70.2 & 182.87 & 0 & 41 & 125.3 & 212.28 & 87.02 & 73 & 233.9 & 81.91 & 18.2 \\
\hline 10 & 71.9 & 211.67 & 0 & 42 & 118.9 & 210.15 & 54.04 & 74 & 237.5 & 76.88 & 12.15 \\
\hline 11 & 71.9 & 214.11 & 0 & 43 & 116.9 & 153.76 & 63.44 & 75 & 236.6 & 62.81 & 5.37 \\
\hline 12 & 71.9 & 224.41 & 0 & 44 & 115.9 & 124.77 & 101.59 & 76 & 236.1 & 56.82 & 2.07 \\
\hline 13 & 70.7 & 158.26 & 0 & 45 & 115.4 & 90.46 & 104.11 & 77 & 215.4 & 34.9 & 0 \\
\hline 14 & 70.7 & 135.45 & 0 & 46 & 115 & 57.35 & 90.68 & 78 & 211 & 23.98 & 0 \\
\hline 15 & 71.3 & 163.1 & 0 & 47 & 124.1 & 96.22 & 91.85 & 79 & 210.9 & 25.11 & 0 \\
\hline 16 & 72 & 175.49 & 0 & 48 & 127.1 & 114.66 & 66.78 & 80 & 210.8 & 23.43 & 0 \\
\hline 17 & 76.5 & 219.38 & 0 & 49 & 130.2 & 94.39 & 77.14 & 81 & 198 & 58.69 & 0 \\
\hline 18 & 77.6 & 250 & 0 & 50 & 131.6 & 86.98 & 63.76 & 82 & 197.9 & 93.67 & 0 \\
\hline 19 & 78.7 & 168.04 & 0 & 51 & 140.7 & 69.47 & 75.46 & 83 & 198.5 & 93.49 & 0 \\
\hline 20 & 78.8 & 124.56 & 0.06 & 52 & 141.8 & 55.77 & 110.46 & 84 & 198.6 & 99.55 & 0 \\
\hline 21 & 90.6 & 170.15 & 0.96 & 53 & 143.9 & 74.36 & 70.57 & 85 & 180.8 & 56.82 & 0 \\
\hline 22 & 93.8 & 201.47 & 2.11 & 54 & 145.5 & 83.41 & 103.15 & 86 & 177.2 & 26.01 & 0 \\
\hline 23 & 94.7 & 231.44 & 4.04 & 55 & 145.5 & 50.33 & 72.79 & 87 & 177.8 & 16.74 & 0 \\
\hline 24 & 94.8 & 250 & 6.54 & 56 & 145.6 & 37.21 & 67.41 & 88 & 177.9 & 6.97 & 0 \\
\hline 25 & 110.5 & 235.01 & 9.18 & 57 & 144.7 & 9.1 & 28.94 & 89 & 161.5 & 18.98 & 0 \\
\hline 26 & 113.1 & 227.59 & 13.4 & 58 & 144.4 & 1.34 & 23.89 & 90 & 147.3 & 23.12 & 0 \\
\hline 27 & 113.9 & 135.9 & 16.29 & 59 & 145.2 & 19.54 & 19.75 & 91 & 147.2 & 44.43 & 0 \\
\hline 28 & 114.3 & 106.25 & 20.19 & 60 & 145.3 & 33.06 & 31.53 & 92 & 147.2 & 55.64 & 0 \\
\hline 29 & 132.2 & 213.81 & 28.8 & 61 & 149.6 & 2.02 & 40.48 & 93 & 117.2 & 92.41 & 0 \\
\hline 30 & 145.4 & 250 & 34.78 & 62 & 150.3 & 0 & 63.95 & 94 & 107.5 & 109.01 & 0 \\
\hline 31 & 145.2 & 221.25 & 31.62 & 63 & 150.1 & 10.47 & 59.41 & 95 & 62 & 73.42 & 0 \\
\hline 32 & 145.1 & 204.14 & 39.61 & 64 & 150 & 16.35 & 50.76 & 96 & 58.7 & 63.8 & 0 \\
\hline
\end{tabular}

Calculating Results. Data will be plugged into the model to get the electricity capacity of the load given by the fan, the selling electricity capacity of fan, the charging electricity capacity given by fan to the storage battery, the electricity capacity of the load given by photovoltaics, the selling electricity capacity of photovoltaics, the charging electricity capacity given by photovoltaics to the storage battery, the electric quantity of load given by buying electricity, buying charging electricity capacity, the load electricity capacity discharged by the storage battery. The situation of power supply can be got. The utilization situation of renewable energy sources and the charging and discharging situation of the storage battery are shown in the following figures: 


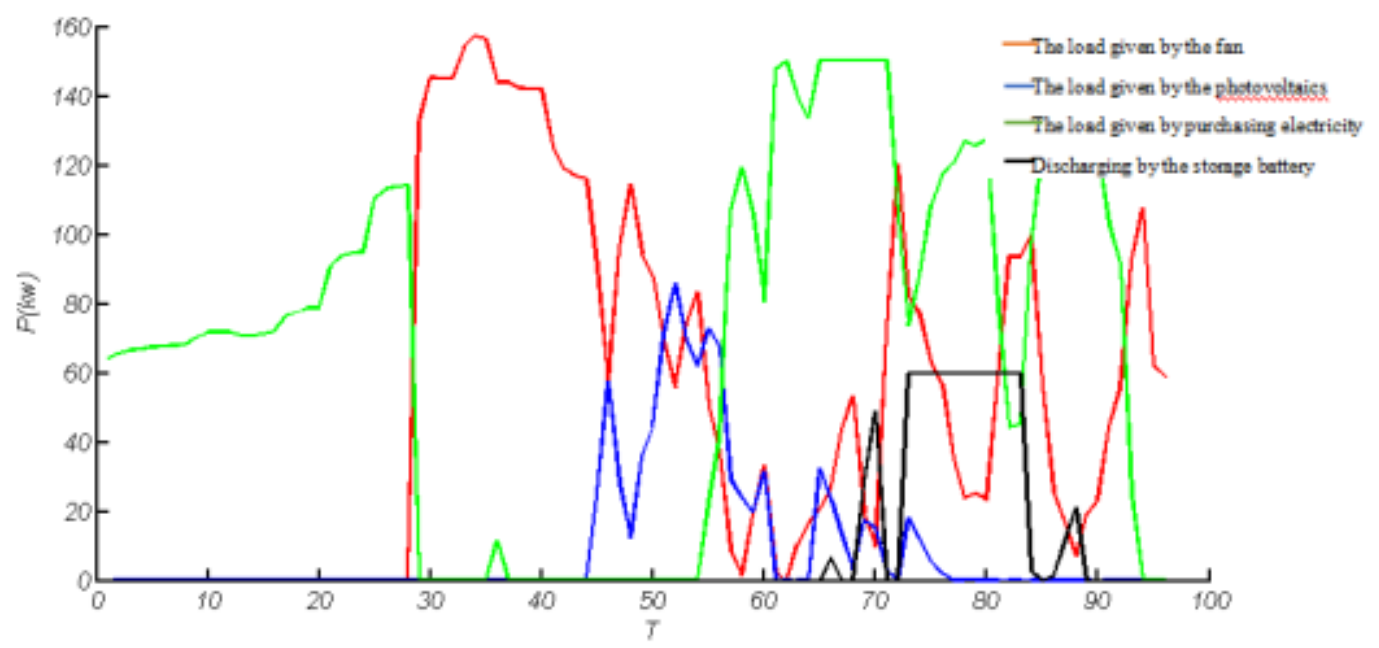

Figure 1 . The power supply situation of the load

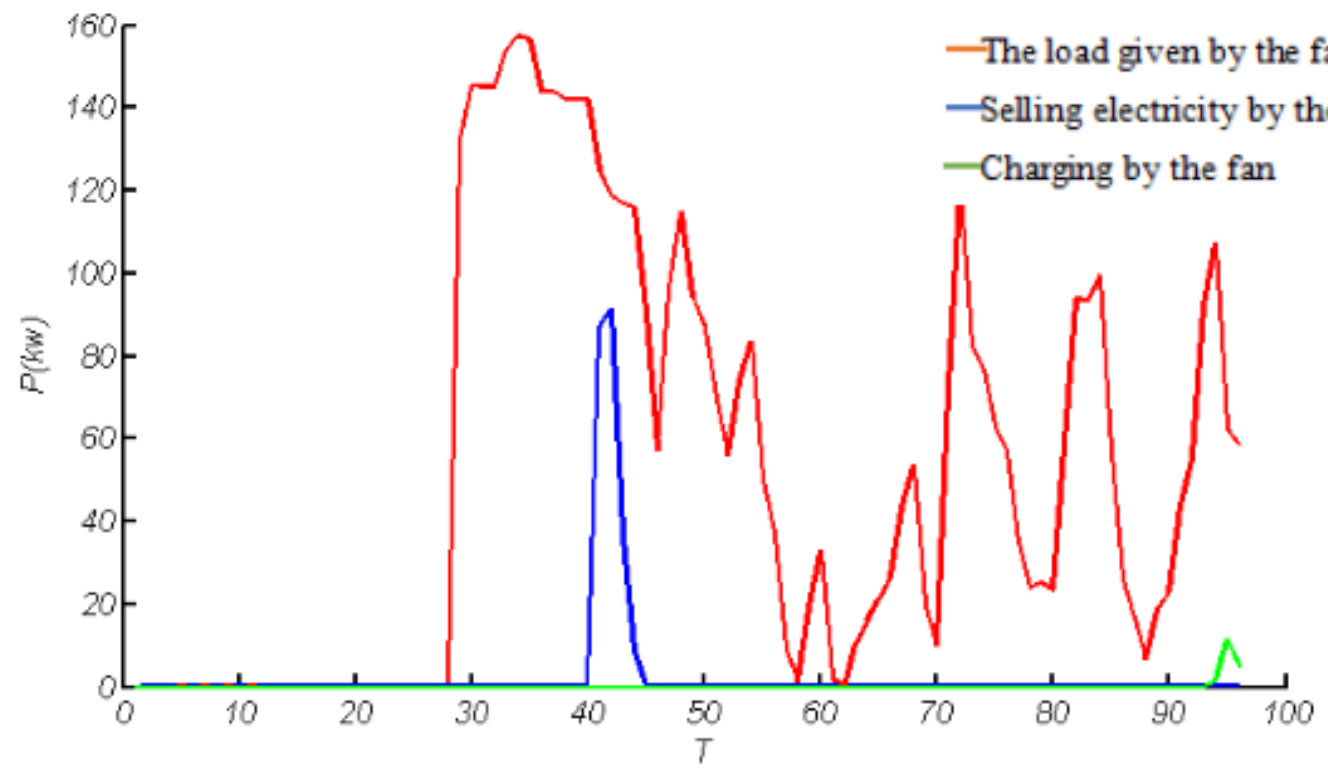

Figure 2. The utilization situation of wind power

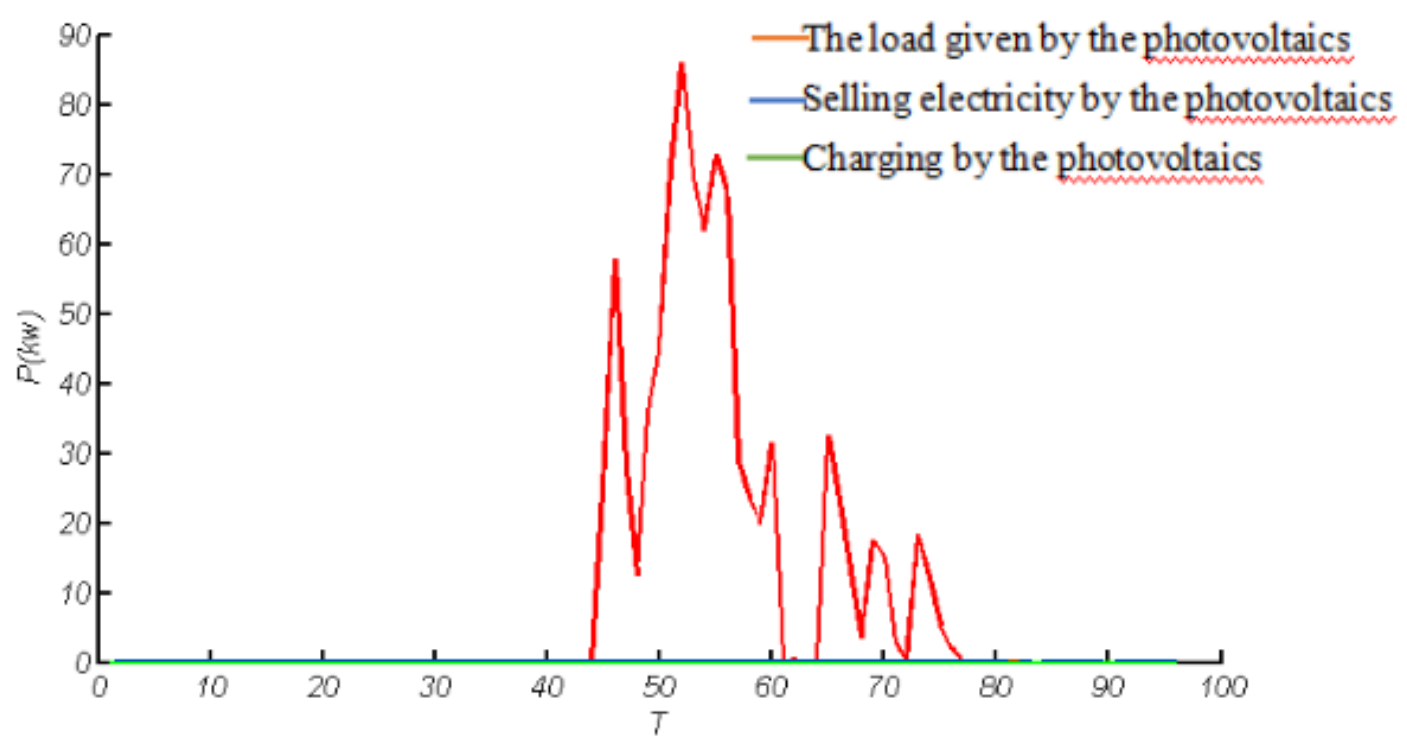

Figure 3. The utilization situation of light power 


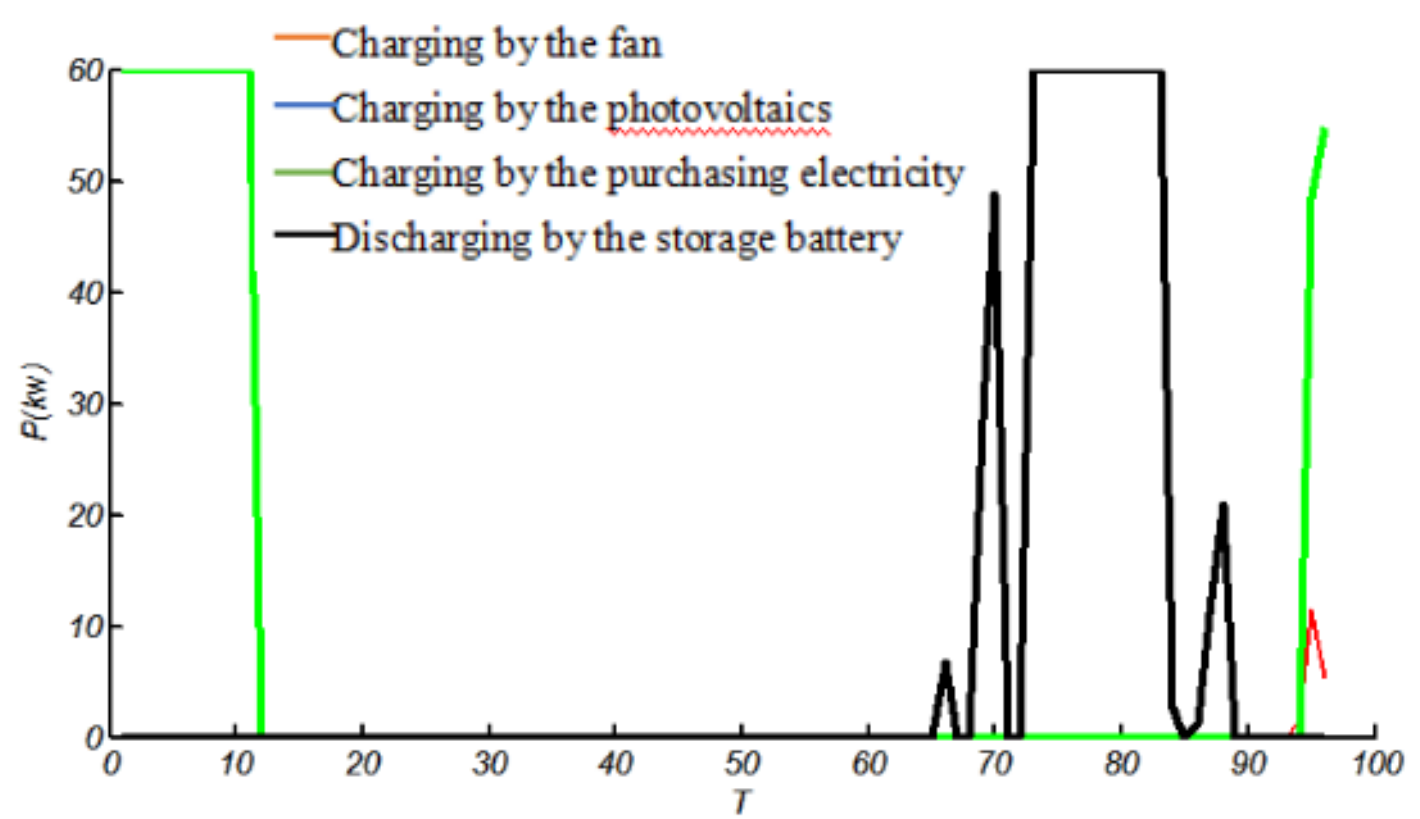

Figure 4. The charging and discharging situation of the storage battery

The total buying fee of electricity for the whole day

$$
C_{Z}=C_{F J}+C_{G F}+C_{G D}+C_{X}-C_{M D}
$$

Among it, $C_{Z}$ stands for the total power supplying fee in the whole day. $C_{F J}$ stands for the total costs of wind power generation. $C_{G F}$ stands for the total costs of photo-voltaic power generation. $C_{G D}$ stands for buying electricity fee from the grid. $C_{X}$ stands for the charging and discharging costs of the storage battery.

The result is that $C_{Z}$ is 1736.0045 yuan. The average unit price of the power supply is 0.52489 yuan $/ \mathrm{kWh}$. It can be concluded that compared with the situation without optimization, the average power supply unit price of the load decreased $(0.688-0.52489) / 0.688=23.71 \%$.

The average purchasing electricity unit price.

$$
C_{A}=\frac{C_{G D}}{0.25 \sum_{i=1}^{96} q_{i}}
$$

The result is that $C_{A}=0.484219$ yuan $/ \mathrm{kWh}$.

Analysis and Conclusion. The first one is the analysis of discharging behavior of the storage battery. Combined with the Figure 4, the reason can be analyzed from the perspective of the lowest cost based on charging for twice and discharging for four times.

Charging process: within 0:00-2:45, the buying price of electricity is the lowest. The buying electricity can charge up the storage battery until the electricity increases to SOC upper limit, and then the buying electricity can stop charging. Within 23:15-24:00, in order to guarantee the beginning state and the ending state of the storage battery energy are equal, the surplus electricity generated from the fan can charge up the storage battery. The lacking part can be replenished by the buying charging method.

Discharging process: within 16: $30,17: 15-17: 45$, the electricity generated by the wind and the light is very low. Because of the low electricity price, after purchasing $150 \mathrm{~kW}$ electricity from the grid, the electricity is still not enough. At this moment, the storage battery can discharge to satisfy the need of the load. Within 18:15-21:00, the electricity generated by the wind and the light is also not enough. However, the electricity price purchased from the grid is high, the storage battery can charge the load at the biggest power in the unit time. The lacking part can be only purchased at the high electricity price. Within 21:30-22:00, there is only the wind power generation and it is very low. Because of the low electricity price, after purchasing $150 \mathrm{~kW}$ electricity from the grid, the 
lacking part can be replenished by the storage battery discharging to satisfy the load.

The second one is the analysis of power supply situation and analysis of utilization situation of renewable energy sources.

Combined with the Figure 1, the power supply situation can be analyzed from the perspective of the lowest cost. Within 0:00-7:00, the buying price of electricity is low and the cost of power generation of renewable energy sources is high, so all the load can be get by purchasing electricity. Within 7:00-10:00, the buying price of electricity increases. At this moment, the load should be provided by lower-cost wind power. The light power should be abandoned. (the wind power undershot at 9:00 so that it can not satisfy the load. The partial load can be supplemented from the main grid.). Within 10:00-11:00, the selling price of electricity is the highest and electricity capacity generated by the wind power is big. The left electricity can be sold to the main grid so that the benefits can be gained. Within 11:00-13:30, the wind power generation can not satisfy the load, but the photovoltaics power generation is very big. The buying price of electricity is high, so the load should be provided by wind power and light power. Within 13:30-15:00, the demand of the load is very big. The power generated by the wind and the light can not satisfy the load. The left load should be only purchased from the grid, even though the buying price of electricity is high. Within 15:00-18:00, the electricity capacity is not enough and the buying price of electricity decreases so that the low-cost wind power and purchasing electricity are both utilized. At the same time, the light power should be abandoned. ( the power generation became zero because of breakdown at 15:30. The load can only be gained by purchasing.) Within 18:00-19:00, the electricity price increases, so the load should be provided by the wind power and the light power. Within 19:00-23:15, there is no photo-voltaic power generation. The electricity capacity generated by the fan can not satisfy the load, so the wind power and the purchasing electricity are utilized to support the load. Within 23:!5-24:00, the wind power can satisfy the load. All the load can be provided by the wind power.

Among them, the electricity price is low at 16:30, 17: 15-17: 45 and 21: 30-22: 00 , so purchasing electricity from the grid can supplement the lacking part. However, the exchange power is limited to $150 \mathrm{~kW}$, so the storage battery should provide the load to supplement the lacking part. Within 18:15-21:00, the electricity price is high, so the storage battery can provide the power supply. The lacking part can be purchased from the grid after the discharging power is biggest.

\section{Conclusion}

Through analyzing the charging and discharging situation of the storage battery, there are two effects caused by the storage battery on the micro-grid running. The first one is that the storage battery can supplement the lacking part that is not provided totally by the wind power and light power. The storage battery can provide the load when the electricity price is high. The storage battery can achieve the lowest supply cost. Meanwhile, under the situation of allowing exchange power between micro-grid and the grid and the selective use of renewable energy resources, the cost of power supply and electricity fee can be reduced so that economy of the micro-grid can be improved through coordinating renewable energy output, the charging and discharging electricity of the storage battery and exchange power of the grid.

\section{References}

[1] W.Huang, T.Huang, H.Zhou, etc: Dynamic Economical Dispatch for Microgrid Based on Improved Differential Evolution Algorithm[J], Automation of Electric Power Systems, 2014,(09):211-217.

[2] P.Xi, P.Li and J.X.Liu: Research on Economic Operation Optimization of Grid-connected Microgrid[J], Electric Power Science and Engineering,2011,(09):1-7.

[3] B.W.Hong, L.Guo, C.S.Wang, etc: Model and Method of Dynamic Multi-objective Optimal Dispatch for Microgrid[J], Electric Power Automation Equipment,2013,(03):100-107.

[4] X.Luo, H.N.Niu, M.H.Yang: Day-ahead Planning Optimization Method of Microgrid Based on the Improved Matrix Real Coding Genetic Algorithm[C], Academic Annual Meeting of Electric 
System and Its Automatism Major of Chinese Universities, 2014.

[5] X.L.Meng, H.N.Niu, D.L.Jia, etc: Real-time Energy Optimal Dispatch for Microgrid Based on Day-ahead Scheduling of Charge State[J], Transactions of Chinese Society of Agricultural Engineering,2016,(08):155-161.

[6] B.W.Hong, L.Guo, C.S.Wang, etc: Model and Method of Dynamic Multi-objective Optimal Dispatch for Microgrid [J], Electric Power Automation Equipment, 2013, 33(3):100-107.

[7] J.Chen, X.Yang, L.Zhu and M.X.Zhang: Comparison of Microgrid Economic Operation among Different Dispatch Modes[J], Electric Power Automation Equipment, 2013,(08):106-113.

[8] Y.H.Liu, N.Zhang and X.Zhang: Economic Operation of Wind-PV-ES Hybrid Microgrid by Considering of Energy Storage Operational Cost[J], Modern Electric Power, 2013,(05):13-18.

[9] Q.G.Yan, X.Y.Meng, Y.Cui, etc: Comprehensive Benefit Evaluation Based on Interaction of Micro-Grid and Distribution Network[J], Electrical \& Energy Management Technology, 2014,(21):47-52+82.

[10] Z.F.Liu, T.Wei, M.Y.Li, etc: Comprehensive Evaluation Based on Improved Analytic Hierarchy Process for AC / DC Microgrid[J], Electric Power Automation Equipment, 2016,(03):60-66+78. 